\title{
Ambulacrarians and the Ancestry of Deuterostome Nervous Systems
}

Laurent Formery, Michael Schubert, Jenifer C. Croce

Affiliation:

L. Formery $\cdot$ M. Schubert · J.C. Croce $(\longrightarrow)$

Sorbonne Université, CNRS, Laboratoire de Biologie du Développement de Villefranche-sur-Mer

(LBDV), Evolution of Intercellular Signaling in Development (EvoInSiDe) Team, 06230 Villefranche-sur-Mer, France

e-mail: jenifer.croce@obs-vlfr.fr 


\begin{abstract}
The evolutionary origin and history of metazoan nervous systems has been at the heart of numerous scientific debates for well over a century. This has been a particularly difficult issue to resolve within the deuterostomes, chiefly due to the distinct neural architectures observed within this group of animals. Deuterostomes feature indeed central nervous systems, apical organs, nerve cords and basiepidermal nerve nets. Comparative analyses investigating the anatomy and molecular composition of deuterostome nervous systems have nonetheless succeeded in identifying a number of shared and derived features. These analyses have led to the elaboration of diverse theories about the origin and evolutionary elaboration of deuterostome nervous systems. Here, we provide an overview of these distinct theories. Further, we argue that deciphering the adult nervous systems of representatives of all deuterostome phyla, including echinoderms, which have long been neglected in this type of surveys, will ultimately provide answers to the questions of the ancestry and evolution of deuterostome nervous systems.
\end{abstract}

\title{
Keywords
}

Nervous system evolution, Deuterostome, Ambulacrarian, Echinoderm, Hemichordate, Chordate. 


\section{X.1 Introduction}

Among metazoans, the deuterostomes constitute one of the two major infrakingdoms of bilaterian animals (Satoh et al. 2014). Members of the deuterostomes include the vertebrates, the tunicates, the cephalochordates, the hemichordates, and the echinoderms, with the former three establishing the chordate superphylum and the latter two constituting the ambulacrarian superphylum (Fig. X.1). Deuterostomes present overall very diverse body plans and lifestyles, which together have significantly hampered the establishment of robust phylogenetic relationships within this part of the animal tree of life (e.g. Blair and Hedges 2005; Lowe et al. 2015). Yet, with the advent of whole genome sequences and molecular phylogenies, the monophyly of the deuterostomes as well as the major phylogenetic branching patterns within this infrakingdom have by now been firmly established (Delsuc et al. 2006; Dunn et al. 2008; Telford et al. 2015).

Of the many characters investigated to understand the ancestry and evolution of the deuterostomes, particular attention has been paid over the years to the nervous system. It turns out, however, that the two major superphyla of deuterostomes, i.e. chordates and ambulacrarians, are characterized by remarkably different nervous systems (Fig. X.1). Chordate larvae commonly form a neural tube that, in the adult, gives rise to a central nervous system with an anterior brain and a posterior spinal cord (Holland 2009). In contrast, ambulacrarian larvae possess a nervous system consisting of an apical organ and of neurons underlying the larval ciliary bands. In addition, these neural structures are subsequently lost during metamorphosis and hence do not contribute to the adult nervous system of ambulacrarians, which is created de novo (Nakajima et al. 2004; Byrne et al. 2007; Miyamoto et al. 2010). The adult nervous system of ambulacrarians, in turn, can also be subdivided into two main structures: a basiepidermal nerve net (or nerve plexus) and nerve cords (i.e. condensed bundles of neurons) (Chia and Burke 1978; Nakano et al. 2006; Miyamoto et al. 2010). Importantly, although it is largely accepted that the last common chordate ancestor possessed a centralized nervous system, the phylogenetic relationships of the chordate central nervous system with the ambulacrarian larval neural structures, adult nerve nets or adult nerve cords are still a matter of debate (Lowe et al. 2003; Haag 2005; Nielsen 2006; Nomaksteinsky et al. 2009; Kaul and Stach 2010; Burke 2011).

Interestingly, comparative analyses carried out in cnidarians, arthropods, annelids, and vertebrates have revealed a certain degree of conservation between neuronal cell types and gene expression patterns in the neurogenic territories of these animals (Marlow et al. 2014; Arendt 2018). These conserved features have hence been interpreted as evidence for a common origin of all eumetazoan (cnidarians + bilaterians) nervous systems and for the presence of a condensed, centralized nervous system in the last common ancestor of bilaterians (i.e. the urbilateria) (Holland 
et al. 2013; Nielsen 2015; Arendt et al. 2016). This hypothesis thus implies the presence of an urbilaterian-like central nervous system in the deuterostome ancestor. However, supplementary surveys conducted on a different selection of bilaterian species have also revealed striking differences in the neuroanatomy, neuronal cell types, and gene expression patterns of these animals compared to the former ones (Hejnol and Lowe 2015; Martín-Durán et al. 2018). These results have led to the contradictory hypothesis that nervous system centralization may have actually taken place independently in distinct bilaterian phyla (Holland 2003; Northcutt 2012). Consequently, to date, the morphology of the nervous system of the last common ancestor of deuterostomes remains elusive (Holland 2015a; Lowe et al. 2015).

To assess the ancestry of deuterostome nervous systems, careful investigations and interpretations of shared and derived traits between chordate and ambulacrarian nervous systems take thus center stage. The developing and adult nervous systems of chordates have already been extensively studied and characterized both at the anatomical and molecular levels (Baker and Bronner-Fraser 1997; Holland 2009; Candiani et al. 2012; Hudson 2016; Osugi et al. 2017; Zieger et al. 2017). Comparatively, our understanding of both the anatomy and molecular organization of the larval and adult nervous systems of hemichordates has improved significantly in the course of the last two decades (Lowe et al. 2003; Nomaksteinsky et al. 2009; Miyamoto et al. 2010; KaulStrehlow et al. 2015). In echinoderms, by contrast, most of our knowledge on their nervous system is based on studies on developing embryos and larvae, while the adult nervous system has so far received much less attention (Burke et al. 2006; Hinman and Burke 2018). The main reason for this focus on early development is the derived, pentaradial body plan of the echinoderm adult, which complicates any kind of comparative studies (Hyman 1955; Holland 2015a). However, as presented here, data from echinoderms, and in particular from adult echinoderms, can and should be included in comparative analyses aimed at reconstructing the evolutionary origin and history of deuterostome nervous systems. In this chapter, we review our current understanding of the anatomy and molecular organization of the larval and adult nervous systems of ambulacrarians and assess their possible homologies with chordate nervous systems. We further propose that detailed investigations of adult nervous system development in ambulacrarians, including in adult echinoderms, have the potential to resolve the long-standing debate about the ancestry of deuterostome nervous systems and might even provide crucial evidence for clarifying the origin of centralized nervous systems in bilaterians.

\section{X.2 The deuterostomes}


The deuterostomes represent a large monophyletic group of animals that is composed of two major superphyla: the chordates and the ambulacrarians (Satoh et al. 2014). In addition to these, it should be highlighted though that the xenoturbellids, a group of marine worms, have been placed by some molecular phylogenies as either sister group of the ambulacrarians (Bourlat et al. 2006; Dunn et al. 2008) or basal to all deuterostomes (Mwinyi et al. 2010). However, further molecular analyses have also grouped the xenoturbellids together with the acoels and the nemertodermatids in a separate phylum, the Xenacoelomorpha, and positioned this phylum as either sister group of the ambulacrarians (Philippe et al. 2011) or basal to all bilaterians (Hejnol et al. 2009; Cannon et al. 2016; Rouse et al. 2016). Thus, given current discordant views on the phylogenetic position of the xenoturbellids, representatives of this animal group have not been considered in this review.

Historically, animals have been grouped together as deuterostomes on the fundamental basis of specific morphological traits (Grobben 1908). The most important of these traits was the fate of the blastopore that, in deuterostomes, was said to become the anus, while the mouth will form secondarily on the opposite side of the archenteron. Other traits included radial cleavage (early cell divisions are parallel or perpendicular to the original body axis), blastula formation (development of a hollow sphere of cells surrounding a fluid-filled cavity), and enterocoely (emergence of the mesoderm by folding from the archenteron). Even though all these developmental features can indeed be found amongst all deuterostomes, they have also been reported by now in several protostome phyla (Hejnol and Martindale 2009; Martín-Durán et al. 2012). Thus, these discoveries have significantly reduced the number of characters exclusively shared by deuterostomes, so-called deuterostome synapomorphies.

As of today, the only unambiguous deuterostome synapomorphy is the presence of a pharynx penetrated by several slits (Dominguez et al. 2002; Gillis et al. 2012; Lowe et al. 2015). In extant hemichordates and chordates, pharyngeal gill slits have been described. They are located posterior to the mouth and contribute to gas exchange and feeding. The homology of these structures in between these animals has further been supported by several anatomical and molecular characters (Rychel and Swalla 2007; Gonzalez and Cameron 2009; Gillis et al. 2012). In extant echinoderms, by contrast, pharyngeal gill slits are generally absent, but the fossil record has revealed compelling evidence for the presence of a pharynx pierced by slits in stem echinoderms (Dominguez et al. 2002). Moreover, a perforated pharynx has also been identified in fossils described as stem deuterostomes (Shu et al. 2001, 2003; Ou et al. 2012), thereby reinforcing the notion that a pharynx penetrated by slits is indeed a true deuterostome synapomorphy.

Some authors have further proposed that an endostyle-associated function, so far reported in chordates and hemichordates, may represent an additional deuterostome synapomorphy (Nielsen 
2012; Lowe et al. 2015; Satoh 2016). In chordates, a pharynx-associated organ, called the endostyle, participates in food particle trapping and contributes to endocrine functions. In hemichordates, even though a well-defined endostyle does not seem to be present, the pharynx as a whole has been shown to serve these two functions (Ruppert 2005; Gonzalez and Cameron 2009). Thus, despite the fact that no endostyle equivalent has so far been reported in echinoderms, an endostyle-like structure or at least function might have already been present in the last common ancestor of all deuterostomes (Nielsen 2012; Lowe et al. 2015; Satoh 2016).

\section{X.2.1 The chordates}

The chordates unite three distinct phyla of which phylogenetic relationship is by now very well established. The cephalochordates (or amphioxus) represent the sister group to a clade established by the tunicates (or urochordates) and the vertebrates and that is often referred to as the olfactores (Delsuc et al. 2006; Satoh et al. 2014). Chordates display overall very distinctive adult body plans, anatomies, and forms (Fig. X.1). Cephalochordates are thin and fusiform (Kardong 2012). Tunicates have their entire adult body embedded in a thick tunic made of cellulose (Holland 2016). Vertebrates exhibit a large variety of adult morphologies, marked, for example, by size differences ranging from $1 \mathrm{~cm}$ in frogs to $30 \mathrm{~m}$ in whales (Webster and Webster 2013). Despite this diversity, all chordates are nonetheless characterized by three specific synapomorphies observed at least at some stage in their life cycle: a muscular post-anal tail, a notochord, and a dorsal neural tube.

The muscular post-anal tail is an elongation of the animal trunk extending beyond the anus (Stach and Kaul 2011). This post-anal tail contains skeletal elements and paired muscles, which are used, for example, for undulatory swimming movements in aquatic species and for balancing or grasping in terrestrial ones. In some chordates, such as cephalochordates and fish, the tail is maintained throughout the whole life cycle, while in others, such as ascidian tunicates and humans, it is only present during embryonic development and subsequently disappears.

The second chordate synapomorphy, the notochord, is a flexible rod-shaped structure derived from the mesoderm (Zhang 2009). It extends all along the anterior-posterior body axis and is located between the digestive tract ventrally and the central nervous system dorsally. In cephalochordates, the notochord acts as the primary axial support of both the larval and the adult body, while, in most tunicates, it is present only in the embryo and is subsequently lost during metamorphosis. In vertebrates, the notochord is found in the embryo and contributes then significantly to the formation of the adult intervertebral discs in the vertebral column.

Finally, the third chordate synapomorphy is the dorsal neural tube. The neural tube is a tubular neuroepithelium with a central lumen. It is derived from the ectoderm and forms in the embryo 
through a characteristic developmental process called neurulation (Colas and Schoenwolf 2001; Lowery and Sive 2004). During neurulation, the embryonic neuroectoderm, which is located dorsal to the notochord, bends inward, rounds up, and fuses, thereby detaching itself from the remaining epidermal ectoderm and coming to lie just underneath it. Eventually, in the adult, the dorsal neural tube will form the chordate central nervous system, with its anterior part generating a dense neural condensation, the brain, while its more posterior portions becoming the spinal cord (Fig. X.1). In addition to the central nervous system, chordate nervous systems further include an extensive peripheral nervous system that includes all nerves, ganglia, and sensory cells of the body outside the central nervous system (Buchanan and Tranel 2009; Shepherd 2017). The peripheral nervous system thus serves as a relay between the body and the central nervous system, connecting all neural receptors and effectors in the body to the central nervous system.

\section{X.2.2 The ambulacrarians}

The ambulacrarians include two phyla, the hemichordates and the echinoderms, which form a monophyletic clade within the deuterostomes (Satoh et al. 2014; Telford et al. 2015). The hemichordates can further be subdivided into two classes, the enteropneusts and the pterobranchs (Osborn et al. 2012; Cannon et al. 2014), while the echinoderms comprise five classes, the crinoids (sea lilies and feather stars), the echinoids (sea urchins), the holothuroids (sea cucumbers), the asteroids (sea stars), and the ophiuroids (brittle stars). Among echinoderms, the crinoids are generally placed basal to two sister groups: the echinozoa (echinoids plus holothuroids) and the asterozoa (asteroids plus ophiuroids), a phylogenetic relationship that has recently been validated by two large-scale molecular analyses (Telford et al. 2014; Reich et al. 2015).

As adults, the morphology of hemichordates and echinoderms differ greatly (Fig. X.1). Hemichordates are fusiform worms with a bilateral body plan composed of three regions, which form anterior to posterior are the prosome, the mesosome, and the metasome. The prosome is also commonly referred to as the proboscis in enteropneusts and the cephalic shield in pterobranchs, while the mesosome corresponds to the collar in enteropneusts and the neck in pterobranchs, and the metasome is called the trunk in both enteropneusts and pterobranchs (Kaul-Strehlow and Röttinger 2015; Miyamoto and Wada 2018). In contrast, in echinoderms, the adult bodies do not display bilateral symmetry. They are instead characterized by a pentaradial body plan. The adult echinoderm is organized along an oral-aboral axis along which five axes (or radii) are organized perpendicular to it (Minsuk et al. 2009). Of note, the number of perpendicular axes may vary and can even be higher in certain asteroid and ophiuroid species. Each axis is further defined by the presence of an ambulacrum, which is a specific area of the shell that holds the internal water 
vascular system and that is characterized by a perforated skeleton through which the tube feet emerge. The areas between the ambulacra are referred to as interambulacra (Serafy and Fell 1985; Mooi and David 2008).

Despite the considerable differences in adult morphology, hemichordates and echinoderms nonetheless share some key features that strongly support their phylogenetic relatedness. First, their representatives chiefly adopt one of two developmental modes: their adult forms develop either indirectly by drastic metamorphosis from a feeding, planctotrophic larva or directly by gradual metamorphosis from a non-feeding, lecithotrophic larva (Raff 1987; Kaul-Strehlow and Röttinger 2015). Second, the larvae of hemichordates (i.e. the tornaria observed in spengelid and ptychoderid enteropneusts) and that of echinoderms (i.e. the vitellaria in crinoids, the echinopluteus in echnoids, the auricularia in holothuroids, the ophiopluteus in ophiuroids, and the bipinnaria and the brachiolaria in asteroids) are very similar. They share a similar body plan with bilateral symmetry (Smith 1997) and are characterized by an ectodermal ciliary band, called the neotroch, which surrounds the mouth and is used for locomotion and food collection (Fig. X.1) (Nielsen 1987). Given these similarities, authors have hence proposed that the last common ancestor of hemichordates and echinoderms developed from a common ancestral larva, called the dipleurula larva, and from which all extant ambulacrarian larvae have emerged (Nielsen 1998; Swalla 2006).

Another key feature shared by hemichordate and echinoderm larvae is the presence, along the digestive tract, of three bilaterally paired coelomic compartments, from which most of the adult structures form (Fig. X.2) (Peterson et al. 2000). From the anterior (or animal) to the posterior (or vegetal) pole of the larva, these three paired coeloms are: the protocoel, mesocoel, and metacoel in hemichordates or the axocoel, hydrocoel, and somatocoel in echinoderms (Peterson et al. 2000). In hemichordates, the larval protocoel, mesocoel, and metacoel will respectively give rise to the adult prosome, mesosome, and metasome (Kaul-Strehlow and Röttinger 2015). In echinoderms, by contrast, the situation is more complex, as the coeloms undergo a dramatic reorganization during formation of the adult body (Peterson et al. 2000; Ezhova et al. 2013, 2014). The axocoel thus contributes to the formation of several adult structures, including most notably the excretory axial organ. The right hydrocoel remains in a rudimentary state, while the left hydrocoel generates the most prominent coelom of the adult body, driving both the pentaradial symmetry and the development of the water vascular system. The right and left somatocoels also grow considerably in size and relocate to the aboral side of the hydrocoel, where they create the fused or non-fused adult perivisceral coeloms, which surround the gut, the gonads, and all other inner organs. Albeit evident ontogenetic differences between hemichordates and echinoderms, the shared origin of their coelomic compartments nonetheless allows comparisons of specific ambulacrarian adult body parts. 
For example, adult hemichordates and echinoderms possess a pulsatile vesicle, filtrating podocytes, and an excretory hydropore, whose developmental origin can be traced back, respectively, to the larval protocoel and axocoel (Willmer 1990; Kaul-Strehlow and Röttinger 2015).

Hemichordates and echinoderms further share significant similarities in the organization of their larval and adult nervous systems (Fig. X.1). The nervous systems of hemichordate and echinoderm larvae for instance are commonly composed of two domains: an apical organ, located above the mouth and containing serotonergic neurons (Byrne et al. 2007), and a system of neurons and neurite bundles associated with the ciliary bands (Nakajima et al. 2004; Miyamoto et al. 2010). In both hemichordates and echinoderms, the larval nervous system is subsequently lost at metamorphosis and the adult nervous system is created de novo (Chia and Burke 1978; Nielsen and Hay-Schmidt 2007; Gonzalez et al. 2018). Similarly, the adult nervous system of both hemichordates and echinoderms is made up of two main comparable components: a diffuse nerve net and nerve cords (Knight-Jones 1952; Smith 1965; Stach et al. 2012). In hemichordates, the nerve net is basiepidermal (located within the epidermis or arranged in one or more layers associated with the epidermis) and it is spread throughout the adult, although it is denser in the proboscis in enteropneusts and in the trunk in pterobranchs (Stach et al. 2012; Miyamoto and Wada 2018). In echinoderms, the nerve net is also basiepidermal and it is uniformly distributed throughout the adult.

In regards to the nerve cords, enteropneust hemichordates display two nerve cords: a dorsal nerve cord that runs from the proboscis anteriorly to the tip of the trunk posteriorly and a ventral nerve cord that is restricted to the trunk. The two nerve cords are further linked, at the boundary between the collar and the trunk, by a circumferential nerve ring. These cords and ring, although called as such, are actually mostly basiepidermal condensations of the basiepidermal nerve net, with the exception of the collar portion of the dorsal cord, also referred to as the collar cord, which is subepidermal (located below the epidermis and separated from it by a basement membrane) (Bullock 1945; Kaul and Stach 2010). In pterobranch hemichordates, several basiepidermal condensations of neurons have also been described. Although not explicitly called nerve cords, these include a ventral stalk nerve, branchial and tentacle nerves, and a dorsal cephalic ganglion that is located in the neck. Even though this ganglion is not subepidermal, it has been proposed to be homologous to the enteropneust collar cord due to anatomical evidence (Stach et al. 2012). Echinoderms generally have five nerve cords, one associated with each ambulacrum. These nerve cords can either be basiepidermal, such as in crinoids and asteroids, or subepidermal, like in echinoids, holothuroids, and ophiuroids. In any event, they are always connected at their proximal ends, on the oral side of the adult, by a set of commissures that form a circumoral nerve ring. 


\section{X.3 On the significance of ambulacrarian larval neural structures for understanding deuterostome nervous system evolution}

In all eumetazoans, the first component of the nervous system to arise during embryogenesis is a pro-neural ectodermal domain called the apical or anterior neuroectoderm (ANE) (also referred to sometimes as the animal pole domain) (Arendt et al. 2016; Range and Wei 2016). The ANE domain commonly forms at the animal pole at the onset of gastrulation. Furthermore, its specification commonly requires the suppression of Wnt signaling activity, which is generally achieved by the expression of a conserved set of Wnt antagonists (Houart et al. 2002; Lagutin et al. 2003; Range et al. 2013). Thus, given the conservation of its position and specification mechanism, the ANE has been suggested to be homologous among eumetazoans and to share a common evolutionary origin dating back to their last common ancestor (Range 2014; Holland 2015a; Arendt et al. 2016), thereby assuming that the last common ancestor of deuterostomes also possessed an ANE.

Subsequently, in chordates, the ANE gives rise to the most anterior region of the dorsal neural tube, which will form the most anterior portion of the adult central nervous system. In vertebrates, for example, the ANE territory will constitute parts of the future telencephalon (Wilson and Houart 2004; Plouhinec et al. 2017). In ambulacrarians, by comparison, the ANE gives rise to the apical organ of the larva that is positioned above the mouth (Nielsen and Hay-Schmidt 2007; Hinman and Burke 2018), and which will subsequently be lost during metamorphosis, along with all neural structures associated with the ciliary band ectoderm (Chia and Burke 1978; Nakano et al. 2006; Kaul-Strehlow et al. 2015; Gonzalez et al. 2018). Despite these different ontogenetic fates of the chordate and ambulacrarian ANE, a number of molecular and anatomical similarities have nonetheless been reported between the anterior neural tube of chordates and the apical organ of ambulacrarians. Indeed, following the specification of the ANE, the subsequent differentiation of this neuroectodermal territory into a brain or an apical organ has been shown to be mediated by a similar core set of neurogenic transcription factors, including Six 3, FoxQ2, Rx, and FoxG (Yankura et al. 2010; Holland et al. 2013; Range 2014). Moreover, at the cellular level, both chordate brains and ambulacrarian apical organs contain clusters of serotonergic neurons, which are characterized by neurites projecting posteriorly (Candiani et al. 2001; Byrne et al. 2007; Stach 2014). Thus, based on these conserved features, chordate brains and ambulacrarian apical organs have frequently been described as being evolutionarily related (Wei et al. 2009; Tosches and Arendt 2013; Arendt et al. 2016).

One of the first theories about the evolutionary history of deuterostome nervous systems taking into account larval stages was that of Garstang (Garstang 1894). In this theory, called the auricularia 
hypothesis, the deuterostome ancestor was postulated to be a sexually mature dipleurula-like larva with an apical organ and a ciliary band (Fig. X.3). From there, Garstang proposed that the chordate central nervous system evolved from the circumoral ciliary band of the ancestral dipleurula, with the two lateral sides of the ciliary band moving dorsally and fusing along the midline thereby enclosing the apical organ and forming a dorsal neural tube. Although praised at first (Harvey 1961; Lacalli 1994) and supported by some lines of anatomical and gene expression data (Nielsen 2012), this theory has however been pushed out of favor then given its incoherence with supplementary phylogenetic, morphological, and molecular analyses (Nieuwenhuys 2002; Holland 2011, 2015a). For instance, studies in several ambulacrarian species have demonstrated that cells of the larval ciliary bands do not contribute to the formation of the adult nerve cords. Furthermore, there is no experimental evidence for a coordinated dorsal shift of the larval ciliary bands, which is generally very difficult to explain from an anatomical point of view given that the ciliary bands are firmly embedded in the general ectoderm of the larva. Despite this conflicting evidence from extant animals, Garstang's theory can however not be completely ruled out, since it is impossible to prove that the morphological modifications this theory assumes may not have occurred in the course of animal evolution.

More recently, an amended version of Garstang's theory was proposed by Tosches and Arendt (Tosches and Arendt 2013). Named the chimeric brain hypothesis, this theory postulates that bilaterian nervous systems evolved from an ancestral state characterized by two separate neuroectodermal territories: an apical neuroectodermal territory and a blastoporal neuroectodermal territory. These two territories then gave rise, respectively, to an apical nervous system (ANS) and a blastoporal nervous system (BNS), which in the course of bilaterian evolution would have merged to generate a single central nervous system with an anterior brain followed by a longitudinal nerve cord (Fig. X.4). Interestingly, this theory is currently well supported by various morphological and molecular analyses carried out in cnidarians, arthropods, annelids, and chordates (Denes et al. 2007; Steinmetz et al. 2010; Arendt et al. 2016), but other comparative analyses have also raised some unresolved issues that warrant further investigations. First, although there is a strong evidence supporting the homology of the ANE, which further supports the existence of an ancestral apical neuroectodermal territory, it cannot formally be ruled out that the molecular mechanisms underlying ANE specification have simply been co-opted independently in several phyla (Raff 2008). For instance, similar mechanisms have also been shown to contribute to patterning other animal territories such as the non-neural ectoderm (Holland et al. 2013). Second, the chimeric brain hypothesis has been elaborated from data issued from a very limited number of taxa. Therefore, it does not take into account the diversity of nervous systems observed among animals, such as for 
instance the nervous system of adult echinoderms, which has been excluded since judged too divergent (Benito-Gutiérrez and Arendt 2009). In addition, when considering additional data issued from a larger variety of animal taxa, the anatomy and molecular makeup of bilaterian nervous systems appears much more diverse than previously thought (Hejnol and Lowe 2015; Martín-Durán et al. 2018).

Focusing on the evolution of deuterostomes, Burke also independently proposed a theory regarding the evolution of their nervous systems, which, to a certain extent, is reminiscent of the chimeric brain hypothesis (Burke 2011). In this "animal/axial" theory, the ambulacrarian nervous system is considered as a bipartite system that has been separated both in time and space, with the larval apical organ of ambulacrarians being homologous to the chordate brain and the adult nerve cords of ambulacrarians being homologous to the chordate spinal cord (Fig. X.5). Although this hypothesis remains highly contested, chiefly due to the same arguments that challenge the chimeric brain hypothesis (Holland 2015a), it nonetheless highlights the importance of considering the ambulacrarian adult nervous system. It indeed points out the significance of investigating in particular the anatomy and molecular organization of their nerve cords for understanding the evolutionary origin and history of deuterostome nervous systems, a point that has further been raised by other authors (Haag 2005; Mashanov et al. 2016).

\section{X.4 On the significance of ambulacrarian adult nerve cords for understanding deuterostome nervous system evolution}

In chordates, the neural tube forms during embryonic development through a process called neurulation (Colas and Schoenwolf 2001; Lowery and Sive 2004). During neurulation, the ectodermal neuroepithelium, located dorsally in the embryo, folds in upon itself and closes over, thereby generating a hollow neural tube, which will later differentiate into a brain anteriorly and a spinal cord posteriorly. Interestingly, ambulacrarian adult nerve cord development has also been demonstrated to include, in some cases, a neurulation-like process. In enteropneust hemichordates, for instance, such a process takes place selectively at the level of the collar cord, i.e. the portion of the dorsal nerve cord that is located in the collar. As in chordates, the enteropneust collar cord neurulation process involves the infolding of an ectodermal neuroepithelium and is mediated by transversely oriented ependymal cells possessing myofilaments (Bateson 1884; Morgan 1894; Bullock 1945; Dawydoff 1948; Knight-Jones 1952; Kaul and Stach 2010; Miyamoto and Wada 2013). In echinoderm holothuroids, ophiuroids, and echinoids, the five adult radial nerve cords have also been demonstrated to be subepidermal, tubular neuroepithelia of ectodermal origin, and in echinoids and holothuroids the radial nerve cords have been shown to form through a 
developmental process resembling chordate neurulation (MacBride 1903; von Ubisch 1913; Mashanov et al. 2007). Thus, based on these similarities, a homology has been proposed between the enteropneust collar cord, the echinoderm radial nerve cords, and the chordate neural tube (Fig. X.6) (Haag 2005; Burke 2011; Luttrell et al. 2012).

Several additional anatomical and molecular lines of evidence further support the homology between the collar cord of enteropneust hemichordates and the neural tube of chordates. First, as in chordate brains, giant nerve cells with contralateral neurite projections and numerous synaptic connections have been identified in the collar cord of enteropneust hemichordates (Bullock 1945; Brown et al. 2008; Kaul and Stach 2010). Second, such as seen in chordates, in which the notochord expresses the signaling molecule Hedgehog and mediates dorsal-ventral patterning of the above neural tube, which expresses the gene encoding the Hedgehog receptor Patched, in enteropneust hemichordates the endoderm stomochord, located underneath the collar cord, expresses Hedgehog, and the collar cord expresses Patched (Miyamoto and Wada 2013). Third, the molecular mechanisms regulating dorsal-ventral patterning of the collar cord in the enteropneust Balanoglossus simodensis and that of the chordate neural tube further share some equivalences, as highlighted by the conserved, staggered expression of dorsal-ventral patterning markers, such as Pax3/7 and Pax2/5/8 (Miyamoto and Wada 2013).

Despite these similarities, the homology between the collar cord of enteropneust hemichordates, the radial nerve cords of echinoderms, and the neural tube of chordates has however been challenged by a number of different observations. First, the morphogenetic movements driving the neurulation-like process in various ambulacrarians are significantly different. For instance, the formation of the collar cord in ptychoderid enteropneusts and of the radial nerve cords in echinoids involves tissue invagination (Morgan 1894; MacBride 1903; von Ubisch 1913; Dawydoff 1948), the collar cord in harrimaniid enteropneusts develops by ingression (Bateson 1884), and the radial nerve cords in the holothuroid Stichopus californicus arise by cavitation (Smiley 1986). It should be added, though, that chordates also display different ways of forming a neural tube, including invagination, ingression, and cavitation. Some species even employ several of these modes for developing distinct portions of their neural tube (Lowery and Sive 2004). Second, while the enteropneust collar cord has been shown to form through a neurulation-like process, an equivalent mechanism does not seem to take place in pterobranchs, in which the cephalic ganglion and the main nerve tracts are simple basiepidermal neural condensations (Rehkämper et al. 1987; Stach et al. 2012). Similarly, in echinoderms, the nerve cords of asteroids and crinoids remain basiepidermal and are not internalized during their ontogeny (Smith 1965; Mashanov et al. 2016; Ezhova et al. 2017). It is thus possible that the neurulation processes identified in some ambulacrarian classes 
might simply reflect a secondary acquisition of this process by convergent evolution rather than being an ancestral, inherited character. This notion is further supported by the fact that pterobranchs and crinoids constitute the most basal class of their respective phylum (Cannon et al. 2014). Taken together, this evidence has led some authors to reject the homology between the enteropneust collar cord, the echinoderm nerve cords, and the chordate neural tube (Ruppert 2005; Nielsen 2006; Kaul and Stach 2010).

The ventral nerve cord of enteropneust hemichordates has also been proposed to be homologous to the chordate neural tube (Fig. X.7). Observations on injured animals have indicated that the responsiveness of the animal could only be negatively impacted when the ventral nerve cord was transected. Cutting of the dorsal nerve cord, and even within the collar cord, did not lead to a loss of responsiveness (Bullock 1940; Knight-Jones 1952). These results thus suggested that the ventral nerve cord, and not the collar cord, is likely to act as an integrative center, comparable to the chordate central nervous system. In accordance with this view, BMP2/4 ligands, which in bilaterian animals are generally expressed on the non-neural side of the dorsal-ventral axis (De Robertis and Sasai 1996; Mizutani and Bier 2008), are expressed dorsally in enteropneust hemichordates (Lowe et al. 2006). Thus, based on this regionalized expression of BMP2/4 and albeit the fact that BMP signaling appears not functionally required for dorsal-ventral patterning in enteropneust hemichordates (Lowe et al. 2006), some authors have considered either the ventral nerve cord or the ventral cord plus the collar cord to be homologous to the chordate neural tube (Nübler-Jung and Arendt 1996; Benito-Gutiérrez and Arendt 2009; Holland et al. 2013; Holland 2015b). In echinoderms, neurophysiological surveys have also determined that, following the reception of sensory input, any of the five radial nerve cords has the capacity to control the behavior of the whole animal (Cobb 1987). Despite this observation, it is still a matter of debate, though, whether or not these findings indicate that the radial nerve cords of echinoderms act as an integrative center, comparable to the chordate central nervous system (Cobb 1995; Haag 2006).

\section{X.5 On the significance of ambulacrarian basiepidermal nerve nets as homologs of chordate neural tubes}

In chordates, patterning of the neural tube, along its anterior-posterior axis, is mediated by a specific core set of genes that are expressed in a precise sequential order along the axis (Holland 2009; Robertshaw and Kiecker 2012). Interestingly, in the directly developing enteropneust hemichordate Saccoglossus kowalevskii, homologs of these genes have been shown to display a similar organization of their expression along the anterior-posterior axis of the ectoderm (Lowe et al. 2003; Aronowicz and Lowe 2006). Thus, the transcription factors Six3 and Nkx2.1, for instance, 
which in chordates are involved in the specification of the most anterior portion of the neural tube (Lagutin et al. 2003), are found expressed in the ectoderm of the proboscis of S. kowalevskii, i.e. the most anterior portion of the animal body. Likewise, the genes $O t x$ and $D b x$, known to be expressed in the vertebrate forebrain and midbrain (Nouri and Awatramani 2017), are confined to the ectoderm of the collar region of the enteropneust, and markers expressed in the vertebrate hindbrain and spinal cord, such as Gbx and the Hox genes (McGinnis and Krumlauf 1992; Rubenstein et al. 1998), are found in the trunk ectoderm of S. kowalevskii.

Similarly, comparable to the situation in the vertebrate hindbrain (Wassarman et al. 1997; Tümpel et al. 2009), Hox gene expression in S. kowalevskii displays spatial collinearity in the trunk ectoderm, with anterior Hox genes displaying a more anterior limit of expression (close to the collar) than posterior Hox genes, presenting a more restricted posterior expression (close to tip of the trunk). Such conservation of the deployment of the core set of transcription factors in the ectoderm of $S$. kowalevskii and the central nervous system of chordates strongly suggests a homology and a common ancestral origin for this genetic circuitry (Lowe et al. 2003; Holland 2003). This notion is further supported by similar findings obtained, through gene expression analyses, in two indirectly developing enteropneust hemichordates, the spengelid Schizocardium californicum (Gonzalez et al. 2017) and the ptychoderid Balanoglossus misakiensis (Kaul-Strehlow et al. 2017).

With that said though, in all surveys carried out so far on hemichordates, the expression of the anterior-posterior patterning genes was always found limited to circumferential domains in the ectoderm of these animals and never associated with the nerve cords (Lowe et al. 2003; Aronowicz and Lowe 2006; Gonzalez et al. 2017; Kaul-Strehlow et al. 2017). Thus, a homologous core set of genes seems to pattern two different tissues in hemichordates and chordates: the general ectoderm and the neurogenic ectoderm, respectively. Alternatively, given that the ectoderm of enteropneust hemichordates harbors a basiepidermal nerve net (Kaul-Strehlow and Röttinger 2015; Miyamoto and Wada 2018), it could be argued, as it has been by some authors, that this basiepidermal nerve net of hemichordates could actually be considered as homologous to the chordate neural tube (Fig. X.8) (Holland 2003). Additional work carried out on S. kowalevskii is in fact supportive of this latter notion (Pani et al. 2012; Yao et al. 2016). It established, for example, that key components controlling the specification of the three signaling centers of the developing vertebrate brain (the anterior neural ridge, the zona limitans intrathalamica, and the isthmic organizer) display similar co-expression patterns again in the enteropneust ectoderm (Pani et al. 2012). In addition, signaling components of the key developmental pathways Wnt, FGF, and Hedgehog have been shown to be expressed in a vertebrate brain-like arrangement in the enteropneust ectoderm and to control 
homologous anterior-posterior patterning mechanisms (Pani et al. 2012). Finally, a cis-regulatory element mediating the localized expression of the signaling molecule Hedgehog in the zona limitans intrathalamica of mice has also been demonstrated as conserved in enteropneusts, in which it functions to direct the expression of Hedgehog to the proboscis-collar boundary of the ectoderm (Yao et al. 2016).

Together, the discovery of a conserved molecular toolkit controlling anterior-posterior patterning of the chordate neural tube and of the enteropneust ectoderm has hence prompted a reassessment of the most plausible hypotheses for nervous system evolution in deuterostomes. To date, two scenarios are being discussed: (1) the deuterostome ancestor had a centralized, chordate-like nervous system or (2) the deuterostome ancestor had a diffuse, enteropneust-like nervous system. In the first scenario, the anterior-posterior patterning machinery of the ancestral centralized nervous system would have been co-opted to control ectodermal development in hemichordates. In the second scenario, the chordate central nervous system would have evolved independently and integrated the ancestral anterior-posterior ectodermal patterning system. In support of the first scenario, as mentioned above, BMP signaling does not seem to be required in enteropneust hemichordates for dorsal-ventral patterning and development of the ectodermal nerve net (Lowe et al. 2006). This contrasts markedly with the situation in other bilaterian animals and has thus been interpreted as evidence for the derived character of the hemichordate nervous system (Holland 2015a). In addition, anatomical and molecular data further suggest that the neurons scattered in the proboscis of enteropneust hemichordates are more likely to constitute a peripheral nervous system than to mark the presence of a centralized nervous system (Nomaksteinsky et al. 2009). In this context, it is important to highlight that the chordate ectoderm is also neurogenic, containing a sophisticated peripheral nervous system that is however never referred to as a nerve net (Holland et al. 2013). In support to the second scenario, by contrast, adult echinoderms also possess a basiepidermal nerve net (Smith 1965), and recent molecular analyses suggest that the expression of at least a subset of the core set of the anterior-posterior neural patterning genes are also expressed in the ectoderm of adult echinoderms (Tsuchimoto and Yamaguchi 2014; Koop et al. 2017; Adachi et al. 2018).

So far, adult echinoderms have largely remained at the margin of the debate on the evolution of deuterostome nervous systems, mainly due to their derived pentaradial body plan and peculiar anatomical characters, such as the water vascular system (Benito-Gutiérrez and Arendt 2009; Holland 2015a). Nonetheless, they must be included in order to resolve the question of the ancestry of deuterostome nervous systems. As of now, only very few studies have attempted to characterize the molecular signature of the nervous system of the developing rudiment or of the adult of 
echinoderms (Tsuchimoto and Yamaguchi 2014; Koop et al. 2017; Adachi et al. 2018). Interestingly, though, when looking at the expression of a selection of anterior-posterior neural patterning genes in echinoderm developing rudiments, this expression did not appear staggered along one of the body axes, but was instead radial around the body associated with either ambulacra or interambulacra. For instance, in the sand dollar Peronella japonica, the transcription factors Six 3 and Otx, and some of the Hox genes were found expressed in all five ambulacra, while Pax 2/5/8 was detected in some interambulacra and Engrailed in all interambulacra (Tsuchimoto and Yamaguchi 2014; Adachi et al. 2018). These data have been interpreted as evidence for a homology of the ambulacra of echinoderms and the proboscis and collar regions of enteropneust hemichordates (Adachi et al. 2018). However, given that the sand dollar P. japonica is characterized by a derived mechanism of adult rudiment formation, which is unique among echinoderms (Tsuchimoto and Yamaguchi 2014), this interpretation certainly requires additional experimental scrutiny.

Despite this last point, expression of the neurogenic genes investigated to date in echinoderm rudiments has always been detected in either the ambulacral or interambulacral ectoderm, and was never restricted to the radial nerve cord territory, hence similar to the situation in enteropneust hemichordates. Thus, regardless of the modified body plan of adult echinoderms, one could argue that a conserved core set of neurogenic genes is similarly deployed in the echinoderm and the hemichordate ectoderm to pattern the developing adult basiepidermal nerve net. Although this notion still requires additional experimental evidence, if corroborated, it would strongly support the idea that the deuterostome ancestor had a diffuse ectodermal nervous system patterned along the anterior-posterior axis by a conserved molecular toolkit. However, in echinoderms, the adult ambulacral ectoderm in fact holds two neural structures: the basiepidermal nerve net and the radial nerve cords (Hyman 1955; Smith 1965). Thus, alternatively, the expression of the neurogenic genes observed to date in the rudiment may secondarily get reorganized in the course of sea urchin development and become associated selectively with the adult radial nerve cords, a scenario that would then contradict the aforementioned hypothesis. As a matter of fact, corresponding gene expression shifts have already been reported, for instance, for the Otx gene in the sea urchin Holopneustes purpurescens (Morris et al. 2004). Thus, given the present status of our knowledge, the question of homology between ambulacrarian and chordate nervous systems remains unresolved, which in turn hampers any conclusion on which of the two proposed scenarios for deuterostome nervous system evolution is correct. 


\section{X.6 Conclusions and future directions}

Understanding the ancestry and evolution of deuterostome nervous systems remains one of the key challenges of comparative biology. Several different theories have been proposed to reconcile the available experimental evidence with possible scenarios about the ancestral deuterostome state and how it evolved to generate the nervous systems of extant chordates and ambulacrarians. Here, we presented an overview of the most widely accepted theories and discussed anatomical, physiological, and molecular data from all deuterostome phyla in a comparative context. This summary work reveals that, albeit their derived pentaradial body plans, adult echinoderms enriched comparative analyses and should thus be included in future studies. Furthermore, we found that strong arguments are still lacking to irrefutably establish homologies between the chordate central nervous system and any kind of ambulacrarian nervous system, larval or adult. Going forward, additional work on adult echinoderms and hemichordates will thus be particularly informative, and thorough investigations of the molecular patterning, anatomy, and neurophysiology of their adult nervous system will be tremendously helpful to obtain an understanding of nervous system evolution in ambulacrarians.

To date, studies on the molecular signatures of adult ambulacrarian nervous systems remain limited to a couple of hemichordate and echinoderm species. For instance, most of the molecular work on hemichordates has so far been carried out solely on the directly developing enteropneust $S$. kowalevskii, while studies on indirectly developing enteropneusts are scarce and those on pterobranchs remain even rarer. In echinoderms, most of the molecular data on adults has also been obtained using mainly either echinoid or holothuroid models. Yet, asteroids and crinoids are characterized by an adult nervous system that is anatomically very different from that of echinoids and holothuroids. Hence, a detailed molecular characterization of their non-tubular basiepidermal nerve cords would be very useful for providing additional information on the possible architecture of the nervous system of the last ambulacrarian ancestor.

In terms of molecular analyses, it will be important also to establish in representatives of all ambulacrarian taxa, whether the BMP signaling pathway is required for the specification of neural territories. While this is the case in most bilaterians, BMP signaling does not seem to control this process in the enteropneust hemichordate $S$. kowalevskii. In echinoids, BMP signaling participates in the positioning of the larval nervous system (Duboc et al. 2004). In addition, during adult rudiment formation, BMP2/4 ligands are expressed in the vestibule ectoderm and the hydrocoelderived podia (Koop et al. 2017). However, whether the BMP signaling pathway is involved in echinoids in the establishment of the adult nervous system remains to be ascertained. Similarly, the roles of the Hedgehog signaling pathway in the development of the adult ambulacrarian nervous 
system need to be characterized exhaustively. In chordates, the Hedgehog pathway is crucially involved in dorsal-ventral patterning of the neural tube (Patten and Placzek 2000; Dessaud et al. 2008), and it has been suggested that a comparable molecular mechanism coordinates collar cord development in enteropneust hemichordates (Miyamoto and Wada 2013). Furthermore, conserved cis-regulatory elements seem to control Hedgehog expression in the brain of chordates and the ectoderm of enteropneust hemichordates (Pani et al. 2012). In echinoderms, mRNAs encoding Hedgehog are detected in the ambulacra of the adult rudiment of the sand dollar P. japonica (Adachi et al. 2018), but the biological relevance of this finding still remains elusive. Finally, it might also be important to assess the level of conservation of the gene regulatory network acting downstream of both the BMP and Hedgehog signaling pathways across deuterostomes. As a matter of fact, gene expression profiles of transcription factors acting downstream of BMP and Hedgehog signaling in dorsal-ventral patterning have already proven to be critical for evaluating homologies of neural structures in protostomes and among bilaterians (Martín-Durán et al. 2018; Arendt 2018).

In sum, we urgently require a more comprehensive understanding of the molecular programs that control the development of ambulacrarian adult nervous systems. Only with this information in hand it will be possible to carry out exhaustive comparisons between ambulacrarians and chordates, which in turn should reveal the evolutionary history of deuterostome nervous systems and provide novel insights into the origin of centralized nervous systems in bilaterians.

\section{Acknowledgements}

The authors would like to thank Lucas Leclère for insightful discussions. Laurent Formery is indebted to the André Picard Network (ANR-11-IDEX-0004-02), the French Ministry of Research and Technology (2173/2015), and the Japan Society for the Promotion of Science (PE18758) for funding and support. 


\section{References}

Adachi S, Niimi I, Sakai Y, et al (2018) Anteroposterior molecular registries in ectoderm of the echinus rudiment. Developmental Dynamics 247:1297-1307. doi: 10.1002/dvdy.24686

Arendt D (2018) Animal Evolution: Convergent Nerve Cords? Current Biology 28:R225-R227. doi: $10.1016 /$ j.cub.2018.01.056

Arendt D, Tosches MA, Marlow H (2016) From nerve net to nerve ring, nerve cord and brain evolution of the nervous system. Nature Reviews Neuroscience 17:61-72. doi: $10.1038 / \mathrm{nrn} .2015 .15$

Aronowicz J, Lowe CJ (2006) Hox gene expression in the hemichordate Saccoglossus kowalevskii and the evolution of deuterostome nervous systems. Integr Comp Biol 46:890-901. doi: 10.1093/icb/icl045

Baker CVH, Bronner-Fraser M (1997) The origins of the neural crest. Part II: an evolutionary perspective. Mechanisms of Development 69:13-29. doi: 10.1016/S09254773(97)00129-9

Bateson W (1884) The Early Stages in the Development of Balanoglossus (sp. incert.). Journal of Cell Science s2-24:208-236

Benito-Gutiérrez È, Arendt D (2009) CNS Evolution: New Insight from the Mud. Current Biology 19:R640-R642. doi: 10.1016/j.cub.2009.06.020

Blair JE, Hedges SB (2005) Molecular Phylogeny and Divergence Times of Deuterostome Animals. Mol Biol Evol 22:2275-2284. doi: 10.1093/molbev/msi225

Bourlat SJ, Juliusdottir T, Lowe CJ, et al (2006) Deuterostome phylogeny reveals monophyletic chordates and the new phylum Xenoturbellida. Nature 444:85-88. doi: 10.1038/nature05241

Brown FD, Prendergast A, Swalla BJ (2008) Man is but a worm: Chordate origins. genesis 46:605-613. doi: 10.1002/dvg.20471

Buchanan TW, Tranel D (2009) Central and peripheral nervous system interactions: From mind to brain to body. Int J Psychophysiol 72:1-4. doi: 10.1016/j.ijpsycho.2008.09.002

Bullock TH (1945) The Anatomical Organization of the Nervous System of Enteropneusta. Journal of Cell Science s2-86:55-111

Bullock TH (1940) The Functional Organization of the Nervous System of Enteropneusta. Biological Bulletin 79:91-113. doi: 10.2307/1537832

Burke RD (2011) Deuterostome neuroanatomy and the body plan paradox. Evolution \& Development 13:110-115. doi: 10.1111/j.1525-142X.2010.00460.x

Burke RD, Angerer LM, Elphick MR, et al (2006) A genomic view of the sea urchin nervous system. Dev Biol 300:434-460. doi: 10.1016/j.ydbio.2006.08.007

Byrne M, Nakajima Y, Chee FC, Burke RD (2007) Apical organs in echinoderm larvae: insights into larval evolution in the Ambulacraria. Evolution \& Development 9:432-445. doi: 10.1111/j.1525-142X.2007.00189.x

Candiani S, Augello A, Oliveri D, et al (2001) Immunocytochemical localization of serotonin in embryos, larvae and adults of the lancelet, Branchiostoma floridae. Histochem J 33:413420

Candiani S, Moronti L, Ramoino P, et al (2012) A neurochemical map of the developing amphioxus nervous system. BMC Neuroscience 13:59. doi: 10.1186/1471-2202-13-59

Cannon JT, Kocot KM, Waits DS, et al (2014) Phylogenomic Resolution of the Hemichordate and Echinoderm Clade. Current Biology 24:2827-2832. doi: 10.1016/j.cub.2014.10.016

Cannon JT, Vellutini BC, Smith J, et al (2016) Xenacoelomorpha is the sister group to Nephrozoa. Nature 530:89-93. doi: 10.1038/nature16520

Chia FS, Burke RD (1978) Echinoderm metamorphosis: fate of larval structures. In: Chia F-S, Rice ME (eds) Settlement and metamorphosis of marine invertebrates, North Holland, NY: 
Elsevier. pp 219-234

Cobb JLS (1987) Neurobiology of the Echinodermata. In: Ali MA (ed) Nervous Systems in Invertebrates. Springer US, Boston, MA, pp 483-525

Cobb JLS (1995) The nervous systems of Echinodermata: Recent results and new approaches. In: Breidbach 0, Kutsch W (eds) The Nervous Systems of Invertebrates: An Evolutionary and Comparative Approach: With a Coda written by T.H. Bullock. Birkhäuser Basel, Basel, pp 407-424

Colas J-F, Schoenwolf GC (2001) Towards a cellular and molecular understanding of neurulation. Developmental Dynamics 221:117-145. doi: 10.1002/dvdy.1144

Dawydoff C (1948) Embranchement des Stomochordes. In: Traite de Zoologie, Anatomie, Systematique, Biologie, Grasse P. P. Paris: Masson, pp 365-532

De Robertis EM, Sasai Y (1996) A common plan for dorsoventral patterning in Bilateria. Nature 380:37-40. doi: 10.1038/380037a0

Delsuc F, Brinkmann H, Chourrout D, Philippe H (2006) Tunicates and not cephalochordates are the closest living relatives of vertebrates. Nature 439:965-968. doi: 10.1038 /nature 04336

Denes AS, Jékely G, Steinmetz PRH, et al (2007) Molecular Architecture of Annelid Nerve Cord Supports Common Origin of Nervous System Centralization in Bilateria. Cell 129:277288. doi: $10.1016 /$ j.cell.2007.02.040

Dessaud E, McMahon AP, Briscoe J (2008) Pattern formation in the vertebrate neural tube: a sonic hedgehog morphogen-regulated transcriptional network. Development 135:24892503. doi: $10.1242 /$ dev.009324

Dominguez P, Jacobson AG, Jefferies RPS (2002) Paired gill slits in a fossil with a calcite skeleton. Nature 417:841-844. doi: 10.1038/nature00805

Duboc V, Röttinger E, Besnardeau L, Lepage T (2004) Nodal and BMP2/4 Signaling Organizes the Oral-Aboral Axis of the Sea Urchin Embryo. Developmental Cell 6:397-410. doi: 10.1016/S1534-5807(04)00056-5

Dunn CW, Hejnol A, Matus DQ, et al (2008) Broad phylogenomic sampling improves resolution of the animal tree of life. Nature 452:745-749. doi: 10.1038/nature06614

Ezhova OV, Ershova NA, Malakhov VV (2017) Microscopic anatomy of the axial complex and associated structures in the sea cucumber Chiridota laevis Fabricius, 1780 (Echinodermata, Holothuroidea). Zoomorphology 136:205-217. doi: 10.1007/s00435016-0341-8

Ezhova OV, Lavrova EA, Malakhov VV (2013) Microscopic anatomy of the axial complex in the starfish Asterias rubens (Echinodermata, Asteroidea). Biol Bull Russ Acad Sci 40:643-653. doi: 10.1134/S1062359013080049

Ezhova OV, Lavrova EA, Malakhov VV (2014) The morphology of the axial complex and associated structures in Asterozoa (Asteroidea, Echinoidea, Ophiuroidea). Russ J Mar Biol 40:153-164. doi: 10.1134/S1063074014030043

Garstang W (1894) Preliminary note on a new theory of the phylogeny of the Chordata. Zoologischer Anzeiger 17:122-125

Gillis JA, Fritzenwanker JH, Lowe CJ (2012) A stem-deuterostome origin of the vertebrate pharyngeal transcriptional network. Proc Biol Sci 279:237-246. doi: 10.1098/rspb.2011.0599

Gonzalez P, Cameron CB (2009) The gill slits and pre-oral ciliary organ of Protoglossus (Hemichordata: Enteropneusta) are filter-feeding structures. Biol J Linn Soc 98:898-906. doi: 10.1111/j.1095-8312.2009.01332.x

Gonzalez P, Jiang JZ, Lowe CJ (2018) The development and metamorphosis of the indirect developing acorn worm Schizocardium californicum (Enteropneusta: Spengelidae). Frontiers in Zoology 15:26. doi: 10.1186/s12983-018-0270-0 
Gonzalez P, Uhlinger KR, Lowe CJ (2017) The Adult Body Plan of Indirect Developing Hemichordates Develops by Adding a Hox-Patterned Trunk to an Anterior Larval Territory. Current Biology 27:87-95. doi: 10.1016/j.cub.2016.10.047

Grobben K (1908) Die systematische Einteilung des Tierreichs. Verhandlungen der KaiserlichKöniglichen Zoologisch-Botanischen Gesellschaft in Wien 58:491-511

Haag ES (2005) Echinoderm rudiments, rudimentary bilaterians, and the origin of the chordate CNS. Evolution \& Development 7:280-281. doi: 10.1111/j.1525142X.2005.05032.X

Haag ES (2006) Reply to Nielsen. Evolution \& Development 8:3-5. doi: 10.1111/j.1525142X.2006.05069.X

Harvey LA (1961) New speculations on the origin of the chordates. Science progress 49:507514

Hejnol A, Lowe CJ (2015) Embracing the comparative approach: how robust phylogenies and broader developmental sampling impacts the understanding of nervous system evolution. Philos Trans R Soc Lond B Biol Sci 370:. doi: 10.1098/rstb.2015.0045

Hejnol A, Martindale MQ (2009) The mouth, the anus , and the blastopore - open questions about questionable openings. In: Telford MJ, Littlewood DTJ (eds) Animal Evolution: Genomes, Fossils, and Trees. Oxford Scholarship Press, pp 33-40

Hejnol A, Obst M, Stamatakis A, et al (2009) Assessing the root of bilaterian animals with scalable phylogenomic methods. Proceedings of the Royal Society of London B: Biological Sciences 276:4261-4270. doi: 10.1098/rspb.2009.0896

Hinman VF, Burke RD (2018) Embryonic neurogenesis in echinoderms. Wiley Interdiscip Rev Dev Biol 7:e316. doi: 10.1002/wdev.316

Holland LZ (2009) Chordate roots of the vertebrate nervous system: expanding the molecular toolkit. Nature Reviews Neuroscience 10:736-746. doi: 10.1038/nrn2703

Holland LZ (2015a) Evolution of basal deuterostome nervous systems. Journal of Experimental Biology 218:637-645. doi: 10.1242/jeb.109108

Holland LZ (2016) Tunicates. Current Biology 26:R146-R152. doi: 10.1016/j.cub.2015.12.024

Holland LZ (2015b) The origin and evolution of chordate nervous systems. Philos Trans R Soc Lond B Biol Sci 370:. doi: 10.1098/rstb.2015.0048

Holland LZ, Carvalho JE, Escriva H, et al (2013) Evolution of bilaterian central nervous systems: a single origin? EvoDevo 4:27. doi: 10.1186/2041-9139-4-27

Holland ND (2003) Early central nervous system evolution: an era of skin brains? Nat Rev Neurosci 4:617-627. doi: 10.1038/nrn1175

Holland ND (2011) Walter Garstang: a retrospective. Theory Biosci 130:247-258. doi: 10.1007/s12064-011-0130-3

Houart C, Caneparo L, Heisenberg C-P, et al (2002) Establishment of the Telencephalon during Gastrulation by Local Antagonism of Wnt Signaling. Neuron 35:255-265. doi: 10.1016/S0896-6273(02)00751-1

Hudson C (2016) The central nervous system of ascidian larvae. Wiley Interdiscip Rev Dev Biol 5:538-561. doi: 10.1002/wdev.239

Hyman LH (1955) The invertebrates. Vol. 4,. McGraw-Hill, New York

Kardong KV (2012) Vertebrates comparative anatomy, function, evolution, 6th ed. New York McGraw-Hill

Kaul S, Stach T (2010) Ontogeny of the collar cord: Neurulation in the hemichordate Saccoglossus kowalevskii. Journal of Morphology 271:1240-1259. doi: 10.1002/jmor.10868

Kaul-Strehlow S, Röttinger E (2015) Hemichordata. In: Wanninger A (ed) Evolutionary Developmental Biology of Invertebrates 6: Deuterostomia. Springer Vienna, pp 59-89

Kaul-Strehlow S, Urata M, Minokawa T, et al (2015) Neurogenesis in directly and indirectly 
developing enteropneusts: of nets and cords. Org Divers Evol 15:405-422. doi: 10.1007/s13127-015-0201-2

Kaul-Strehlow S, Urata M, Praher D, Wanninger A (2017) Neuronal patterning of the tubular collar cord is highly conserved among enteropneusts but dissimilar to the chordate neural tube. Scientific Reports 7:7003. doi: 10.1038/s41598-017-07052-8

Knight-Jones EW (1952) On the nervous system of Saccoglossus cambrensis (Enteropneusta). Phil Trans R Soc Lond B 236:315-354. doi: 10.1098/rstb.1952.0004

Koop D, Cisternas P, Morris VB, et al (2017) Nodal and BMP expression during the transition to pentamery in the sea urchin Heliocidaris erythrogramma: insights into patterning the enigmatic echinoderm body plan. BMC Dev Biol 17:4. doi: 10.1186/s12861-017-0145-1

Lacalli TC (1994) Apical Organs, Epithelial Domains, and the Origin of the Chordate Central Nervous System. Integr Comp Biol 34:533-541. doi: 10.1093/icb/34.4.533

Lagutin OV, Zhu CC, Kobayashi D, et al (2003) Six3 repression of Wnt signaling in the anterior neuroectoderm is essential for vertebrate forebrain development. Genes Dev 17:368-379. doi: $10.1101 /$ gad.1059403

Lowe CJ, Clarke DN, Medeiros DM, et al (2015) The deuterostome context of chordate origins. Nature 520:456-465. doi: 10.1038/nature14434

Lowe CJ, Terasaki M, Wu M, et al (2006) Dorsoventral Patterning in Hemichordates: Insights into Early Chordate Evolution. PLOS Biology 4:e291. doi: 10.1371/journal.pbio.0040291

Lowe CJ, Wu M, Salic A, et al (2003) Anteroposterior Patterning in Hemichordates and the Origins of the Chordate Nervous System. Cell 113:853-865. doi: 10.1016/S00928674(03)00469-0

Lowery LA, Sive H (2004) Strategies of vertebrate neurulation and a re-evaluation of teleost neural tube formation. Mechanisms of Development 121:1189-1197. doi: 10.1016/j.mod.2004.04.022

Luttrell S, Konikoff C, Byrne A, et al (2012) Ptychoderid Hemichordate Neurulation without a Notochord. Integr Comp Biol 52:829-834. doi: 10.1093/icb/ics117

MacBride EW (1903) VI. The development of Echinus esculentus, together some points the development of E. miliaris and E. acutus. Philosophical Transactions of the Royal Society of London Series B, Containing Papers of a Biological Character 195:285-327. doi: 10.1098/rstb.1903.0006

Marlow H, Tosches MA, Tomer R, et al (2014) Larval body patterning and apical organs are conserved in animal evolution. BMC Biology 12:7. doi: 10.1186/1741-7007-12-7

Martín-Durán JM, Janssen R, Wennberg S, et al (2012) Deuterostomic Development in the Protostome Priapulus caudatus. Current Biology 22:2161-2166. doi: 10.1016/j.cub.2012.09.037

Martín-Durán JM, Pang K, Børve A, et al (2018) Convergent evolution of bilaterian nerve cords. Nature 553:45-50. doi: 10.1038/nature25030

Mashanov VS, Zueva OR, Heinzeller T, et al (2007) Developmental origin of the adult nervous system in a holothurian: an attempt to unravel the enigma of neurogenesis in echinoderms. Evolution \& Development 9:244-256. doi: 10.1111/j.1525142X.2007.00157.X

Mashanov VS, Zueva OR, Rubilar T, et al (2016) Echinodermata. In: Schmidt-Rhaesa A, Harzsch S, Purschke G (eds) Structure and evolution of invertebrate nervous systems. Oxford University Press, pp 665-688

McGinnis W, Krumlauf R (1992) Homeobox genes and axial patterning. Cell 68:283-302. doi: 10.1016/0092-8674(92)90471-N

Minsuk SB, Turner FR, Andrews ME, Raff RA (2009) Axial patterning of the pentaradial adult echinoderm body plan. Dev Genes Evol 219:89-101. doi: 10.1007/s00427-009-0270-3

Miyamoto N, Nakajima Y, Wada H, Saito Y (2010) Development of the nervous system in the 
acorn worm Balanoglossus simodensis: insights into nervous system evolution. Evolution \& Development 12:416-424. doi: 10.1111/j.1525-142X.2010.00428.X

Miyamoto N, Wada H (2018) Hemichordate Nervous System. Oxford Research Encyclopedia, Neuroscience 1-20. doi: 10.1093/acrefore/9780190264086.013.204

Miyamoto N, Wada H (2013) Hemichordate neurulation and the origin of the neural tube. Nature Communications 4:2713. doi: 10.1038/ncomms3713

Mizutani CM, Bier E (2008) EvoD/Vo: the origins of BMP signalling in the neuroectoderm. Nature Reviews Genetics 9:663-677. doi: 10.1038/nrg2417

Mooi R, David B (2008) Radial Symmetry, the Anterior/Posterior Axis, and Echinoderm Hox Genes. Annu Rev Ecol Evol Syst 39:43-62. doi:

10.1146/annurev.ecolsys.39.110707.173521

Morgan TH (1894) The development of Balanoglossus. Journal of Morphology 9:1-86. doi: 10.1002/jmor.1050090102

Morris VB, Zhao J-T, Shearman DCA, et al (2004) Expression of an Otx gene in the adult rudiment and the developing central nervous system in the vestibula larva of the sea urchin Holopneustes purpurescens. Int J Dev Biol 48:17-22. doi: 10.1387/ijdb.15005570

Mwinyi A, Bailly X, Bourlat SJ, et al (2010) The phylogenetic position of Acoela as revealed by the complete mitochondrial genome of Symsagittifera roscoffensis. BMC Evolutionary Biology 10:309. doi: 10.1186/1471-2148-10-309

Nakajima Y, Kaneko H, Murray G, Burke RD (2004) Divergent patterns of neural development in larval echinoids and asteroids. Evolution \& Development 6:95-104. doi:

10.1111/j.1525-142X.2004.04011.X

Nakano H, Murabe N, Amemiya S, Nakajima Y (2006) Nervous system development of the sea cucumber Stichopus japonicus. Dev Biol 292:205-212. doi: 10.1016/j.ydbio.2005.12.038

Nielsen C (2006) Homology of echinoderm radial nerve cords and the chordate neural tube??? Evolution \& Development 8:1-2. doi: 10.1111/j.1525-142X.2006.05068.x

Nielsen C (2015) Larval nervous systems: true larval and precocious adult. Journal of Experimental Biology 218:629-636. doi: 10.1242/jeb.109603

Nielsen C (2012) Animal Evolution: Interrelationships of the Living Phyla. OUP Oxford

Nielsen C (1987) Structure and Function of Metazoan Ciliary Bands and Their Phylogenetic Significance. Acta Zoologica 68:205-262. doi: 10.1111/j.1463-6395.1987.tb00892.x

Nielsen C (1998) Origin and evolution of animal life cycles. Biological Reviews 73:125-155. doi: 10.1111/j.1469-185X.1997.tb00027.x

Nielsen C, Hay-Schmidt A (2007) Development of the enteropneust Ptychodera flava: Ciliary bands and nervous system. Journal of Morphology 268:551-570. doi: 10.1002/jmor.10533

Nieuwenhuys R (2002) Deuterostome brains: synopsis and commentary. Brain Research Bulletin 57:257-270. doi: 10.1016/S0361-9230(01)00668-2

Nomaksteinsky M, Röttinger E, Dufour HD, et al (2009) Centralization of the Deuterostome Nervous System Predates Chordates. Current Biology 19:1264-1269. doi: 10.1016/j.cub.2009.05.063

Northcutt RG (2012) Evolution of centralized nervous systems: Two schools of evolutionary thought. PNAS 109:10626-10633. doi: 10.1073/pnas.1201889109

Nouri N, Awatramani R (2017) A novel floor plate boundary defined by adjacent En1 and Dbx1 microdomains distinguishes midbrain dopamine and hypothalamic neurons. Development 144:916-927. doi: 10.1242/dev.144949

Nübler-Jung K, Arendt D (1996) Enteropneusts and chordate evolution. Current Biology 6:352-353. doi: 10.1016/S0960-9822(02)00491-8

Osborn KJ, Kuhnz LA, Priede IG, et al (2012) Diversification of acorn worms (Hemichordata, Enteropneusta) revealed in the deep sea. Proceedings of the Royal Society of London B: 
Biological Sciences 279:1646-1654. doi: 10.1098/rspb.2011.1916

Osugi T, Sasakura Y, Satake H (2017) The nervous system of the adult ascidian Ciona intestinalis Type A (Ciona robusta): Insights from transgenic animal models. PLOS ONE 12:e0180227. doi: 10.1371/journal.pone.0180227

Ou Q, Morris SC, Han J, et al (2012) Evidence for gill slits and a pharynx in Cambrian vetulicolians: implications for the early evolution of deuterostomes. BMC Biology 10:81. doi: 10.1186/1741-7007-10-81

Pani AM, Mullarkey EE, Aronowicz J, et al (2012) Ancient deuterostome origins of vertebrate brain signalling centres. Nature 483:289-294. doi: 10.1038/nature10838

Patten I, Placzek M (2000) The role of Sonic hedgehog in neural tube patterning. CMLS, Cell Mol Life Sci 57:1695-1708. doi: 10.1007/PL00000652

Peterson KJ, Arenas-Mena C, Davidson EH (2000) The A/P axis in echinoderm ontogeny and evolution: evidence from fossils and molecules. Evolution \& Development 2:93-101. doi: 10.1046/j.1525-142x.2000.00042.x

Philippe H, Brinkmann H, Copley RR, et al (2011) Acoelomorph flatworms are deuterostomes related to Xenoturbella. Nature 470:255-258. doi: 10.1038/nature09676

Plouhinec J-L, Medina-Ruiz S, Borday C, et al (2017) A molecular atlas of the developing ectoderm defines neural, neural crest, placode, and nonneural progenitor identity in vertebrates. PLOS Biology 15:e2004045. doi: 10.1371/journal.pbio.2004045

Raff RA (1987) Constraint, flexibility, and phylogenetic history in the evolution of direct development in sea urchins. Dev Biol 119:6-19. doi: 10.1016/0012-1606(87)90201-6

Raff RA (2008) Origins of the other metazoan body plans: the evolution of larval forms. Philosophical Transactions of the Royal Society B: Biological Sciences 363:1473-1479. doi: $10.1098 /$ rstb.2007.2237

Range R (2014) Specification and positioning of the anterior neuroectoderm in deuterostome embryos. genesis 52:222-234. doi: 10.1002/dvg.22759

Range RC, Angerer RC, Angerer LM (2013) Integration of Canonical and Noncanonical Wnt Signaling Pathways Patterns the Neuroectoderm Along the Anterior-Posterior Axis of Sea Urchin Embryos. PLOS Biology 11:e1001467. doi: 10.1371/journal.pbio.1001467

Range RC, Wei Z (2016) An anterior signaling center patterns and sizes the anterior neuroectoderm of the sea urchin embryo. Development 143:1523-1533. doi: 10.1242/dev.128165

Rehkämper G, Welsch U, Dilly PN (1987) Fine structure of the ganglion of Cephalodiscus gracilis (pterobranchia, hemichordata). Journal of Comparative Neurology 259:308-315. doi: 10.1002/cne.902590210

Reich A, Dunn C, Akasaka K, Wessel G (2015) Phylogenomic Analyses of Echinodermata Support the Sister Groups of Asterozoa and Echinozoa. PLOS ONE 10:e0119627. doi: 10.1371/journal.pone.0119627

Robertshaw E, Kiecker C (2012) Phylogenetic Origins of Brain Organisers. Scientifica. doi: $10.6064 / 2012 / 475017$

Rouse GW, Wilson NG, Carvajal JI, Vrijenhoek RC (2016) New deep-sea species of Xenoturbella and the position of Xenacoelomorpha. Nature 530:94-97. doi: 10.1038/nature16545

Rubenstein JLR, Shimamura K, Martinez S, Puelles L (1998) Regionalization of the Prosencephalic Neural Plate. Annual Review of Neuroscience 21:445-477. doi: 10.1146/annurev.neuro.21.1.445

Ruppert EE (2005) Key characters uniting hemichordates and chordates : homologies or homoplasies? 1

Rychel AL, Swalla BJ (2007) Development and evolution of chordate cartilage. Journal of Experimental Zoology Part B: Molecular and Developmental Evolution 308B:325-335. doi: 10.1002/jez.b.21157 
Satoh N (2016) Chordate Origins and Evolution: The Molecular Evolutionary Road to Vertebrates. Academic Press

Satoh N, Rokhsar D, Nishikawa T (2014) Chordate evolution and the three-phylum system. Proceedings of the Royal Society B: Biological Sciences 281:20141729. doi: 10.1098/rspb.2014.1729

Serafy DK, Fell FJ (1985) Marine Flora and Fauna of the Northeastern United States. Echinodermata: Echinoidea. In: National Oceanic and Atmospheric Administration Technical Report NMFS 33. pp 1-27

Shepherd SV (2017) The Wiley Handbook of Evolutionary Neuroscience. John Wiley \& Sons Shu D, Morris SC, Han J, et al (2001) Primitive deuterostomes from the Chengjiang Lagerstätte (Lower Cambrian, China). Nature 414:419-424. doi: 10.1038/35106514

Shu D, Morris SC, Zhang ZF, et al (2003) A New Species of Yunnanozoan with Implications for Deuterostome Evolution. Science 299:1380-1384. doi: 10.1126/science.1079846

Smiley S (1986) Metamorphosis of Stichopus californicus (Echinodermata: Holothuroidea) and Its Phylogenetic Implications. Biological Bulletin 171:611-631. doi: 10.2307/1541627

Smith AB (1997) Echinoderm Larvae and Phylogeny. Annu Rev Ecol Syst 28:219-241. doi: 10.1146/annurev.ecolsys.28.1.219

Smith JE (1965) Echinodermata. In: Bullock TH, Horridge GA (eds) Structure and Function in the Nervous Systems of Invertebrates. Vol. II. W. H. Freeman and Company, London, pp 1519-1558

Stach T (2014) Deuterostome phylogeny - a morphological perspective. In: Wägele JW, Bartolomaeus T (eds) Deep Metazoan Phylogeny: The Backbone of the Tree of Life. De Gruyter, pp 425-457

Stach T, Gruhl A, Kaul-Strehlow S (2012) The central and peripheral nervous system of Cephalodiscus gracilis (Pterobranchia, Deuterostomia). Zoomorphology 131:11-24. doi: 10.1007/s00435-011-0144-x

Stach T, Kaul S (2011) The postanal tail of the enteropneust Saccoglossus kowalevskii is a ciliary creeping organ without distinct similarities to the chordate tail. Acta Zoologica 92:150-160. doi: 10.1111/j.1463-6395.2010.00462.x

Steinmetz PR, Urbach R, Posnien N, et al (2010) Six3 demarcates the anterior-most developing brain region in bilaterian animals. EvoDevo 1:14. doi: 10.1186/2041-9139-114

Swalla BJ (2006) Building divergent body plans with similar genetic pathways. Heredity 97:235-243. doi: 10.1038/sj.hdy.6800872

Telford MJ, Budd GE, Philippe H (2015) Phylogenomic Insights into Animal Evolution. Current Biology 25:R876-R887. doi: 10.1016/j.cub.2015.07.060

Telford MJ, Lowe CJ, Cameron CB, et al (2014) Phylogenomic analysis of echinoderm class relationships supports Asterozoa. Proc Biol Sci 281:. doi: 10.1098/rspb.2014.0479

Tosches MA, Arendt D (2013) The bilaterian forebrain: an evolutionary chimaera. Current Opinion in Neurobiology 23:1080-1089. doi: 10.1016/j.conb.2013.09.005

Tsuchimoto J, Yamaguchi M (2014) Hox expression in the direct-type developing sand dollar Peronella japonica: Hox Expression in an Echinoid. Developmental Dynamics 243:10201029. doi: 10.1002/dvdy.24135

Tümpel S, Wiedemann LM, Krumlauf R (2009) Chapter 8 Hox Genes and Segmentation of the Vertebrate Hindbrain. In: Current Topics in Developmental Biology. Academic Press, pp 103-137

von Ubisch L (1913) Die Entwicklung con Strongylocentrotus lividus. Zeitschrift für wissenschaftliche Zoologie 106:

Wassarman KM, Lewandoski M, Campbell K, et al (1997) Specification of the anterior hindbrain and establishment of a normal mid/hindbrain organizer is dependent on Gbx2 
gene function. Development 124:2923-2934

Webster D, Webster M (2013) Comparative Vertebrate Morphology. Academic Press

Wei Z, Yaguchi J, Yaguchi S, et al (2009) The sea urchin animal pole domain is a Six3dependent neurogenic patterning center. Development 136:1179-1189. doi: 10.1242/dev.032300

Willmer P (1990) Invertebrate Relationships: Patterns in Animal Evolution. Cambridge University Press

Wilson SW, Houart C (2004) Early Steps in the Development of the Forebrain. Developmental Cell 6:167-181. doi: 10.1016/S1534-5807(04)00027-9

Yankura KA, Martik ML, Jennings CK, Hinman VF (2010) Uncoupling of complex regulatory patterning during evolution of larval development in echinoderms. BMC Biology 8:143. doi: 10.1186/1741-7007-8-143

Yao Y, Minor PJ, Zhao Y-T, et al (2016) Cis-regulatory architecture of a brain signaling center predates the origin of chordates. Nature Genetics 48:575-580. doi: 10.1038/ng.3542

Zhang G (2009) An evo-devo view on the origin of the backbone: evolutionary development of the vertebrae. Integr Comp Biol 49:178-186. doi: 10.1093/icb/icp061

Zieger E, Candiani S, Garbarino G, et al (2017) Roles of Retinoic Acid Signaling in Shaping the Neuronal Architecture of the Developing Amphioxus Nervous System. Mol Neurobiol 120. doi: $10.1007 / s 12035-017-0727-8$ 


\section{Figure captions}

Figure X.1. Phylogeny of deuterostomes and schematics of their main neural structures. The tree is based on the current consensus of the phylogenetic relationships between the five extant deuterostome phyla. Vertebrates are represented by frogs, tunicates by ascidians, cephalochordates by amphioxus, hemichordates by enteropneusts, and echinoderms by asteroids. The neural features are indicated in blue for both larva (left panel) and adult (right panel). For chordates, only the central nervous system is highlighted.

Figure X.2. Schematic representation of the coelomic architecture of hemichordate (using enteropneusts as example) and echinoderm (using echinoids as example) larvae and adults (adapted from Peterson et al. 2000 and Tsuchimoto and Yamaguchi 2014). The generalized dipleurula larva of ambulacrarians has five coeloms that will give rise to different adult structures. In hemichordates, the adult inherits the body plan of the larva. In echinoderms, the bilateral larva is reorganized into an adult with pentaradial symmetry. In echinoids, the adult mouth opens on the left of the larva and the oral-aboral axis of the adult is thus perpendicular to the anterior-posterior axis of the larva. However, note that the relative positioning of larval anterior-posterior and adult oralaboral axes is not conserved between the five echinoderm classes (for a review see Peterson et al., 2000; Smiley, 1986). In all schematics the gut is shown in light yellow. Abbreviations: A, anterior; $\mathrm{P}$, posterior.

Figure X.3. Schematic representation of the auricularia hypothesis for the evolution of deuterostome nervous systems (adapted from Garstang 1894). Deuterostome phylogeny and main neural features are according to Fig. X.1. Proposed homologous neural structures are in blue. Proposed derived neural structures are in grey.

Figure X.4. Schematic representation of the chimeric brain hypothesis for the evolution of deuterostome nervous systems (adapted from Tosches and Arendt 2013). Deuterostome phylogeny and main neural features are according to Fig. X.1. Proposed homologous neural structures are highlighted in identical colors. Proposed derived neural structures are shown in grey. The question mark indicates that the nervous system of adult echinoderms was not taken into consideration in the context of this hypothesis. Abbreviations: ANS, apical nervous system; BNS, blastoporal nervous system. 
Figure X.5. Schematic representation of the "animal/axial" hypothesis for the evolution of deuterostome nervous systems (adapted from Burke 2011). Deuterostome phylogeny and main neural features are according to Fig. X.1. Proposed homologous neural structures are highlighted in identical colors. Proposed derived neural structures are shown in grey. The question mark indicates that the ancestral deuterostome state was not defined in this hypothesis.

Figure X.6. Schematic representation illustrating the homology of the chordate neural tube, the enteropneust collar cord, and the echinoderm radial nerve cords (supported by Haag 2005; Burke 2011; Luttrell et al. 2012). Deuterostome phylogeny and main neural features are according to Fig. X.1. Proposed homologous neural structures are in blue. Proposed derived neural structures are in grey. The question mark indicates that the ancestral deuterostome state was not considered in this theory.

Figure X.7. Schematic representation illustrating the homology of the chordate neural tube, the enteropneust ventral nerve cord, and the echinoderm radial nerve cords (supported by Bullock 1940; Knight-Jones 1952; Cobb 1987). Deuterostome phylogeny and main neural features are according to Fig. X.1. Proposed homologous neural structures are in blue. Proposed derived neural structures are in grey. The question mark indicates that the ancestral deuterostome state was not considered in this theory.

Figure X.8. Schematic representation of the ancestral nerve net hypothesis (adapted from Holland 2015a and supported by Lowe et al. 2003). Deuterostome phylogeny and main neural features are according to Fig. X.1. Proposed homologous neural structures are in blue. Proposed derived neural structures are in grey. 

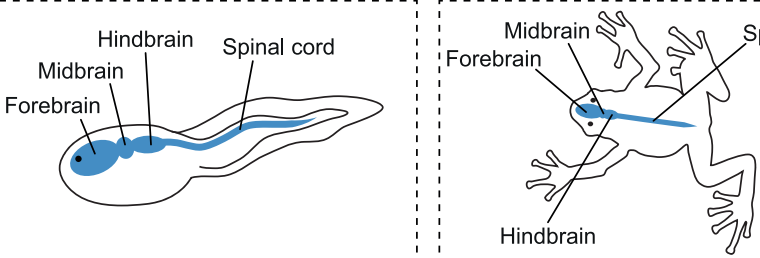

Cerebral vesicle
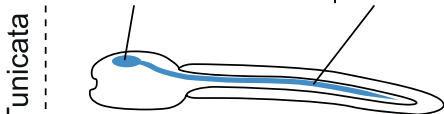

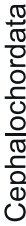

Cerebral vesicle

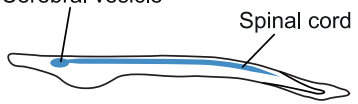

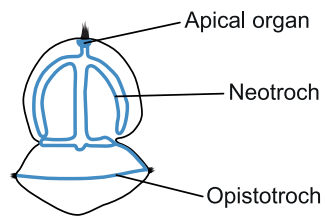

$\frac{\sigma}{\frac{\pi}{2}}$
$\frac{\pi}{0}$
$\frac{\pi}{2}$
$\frac{2}{E}$
$\frac{E}{4}$
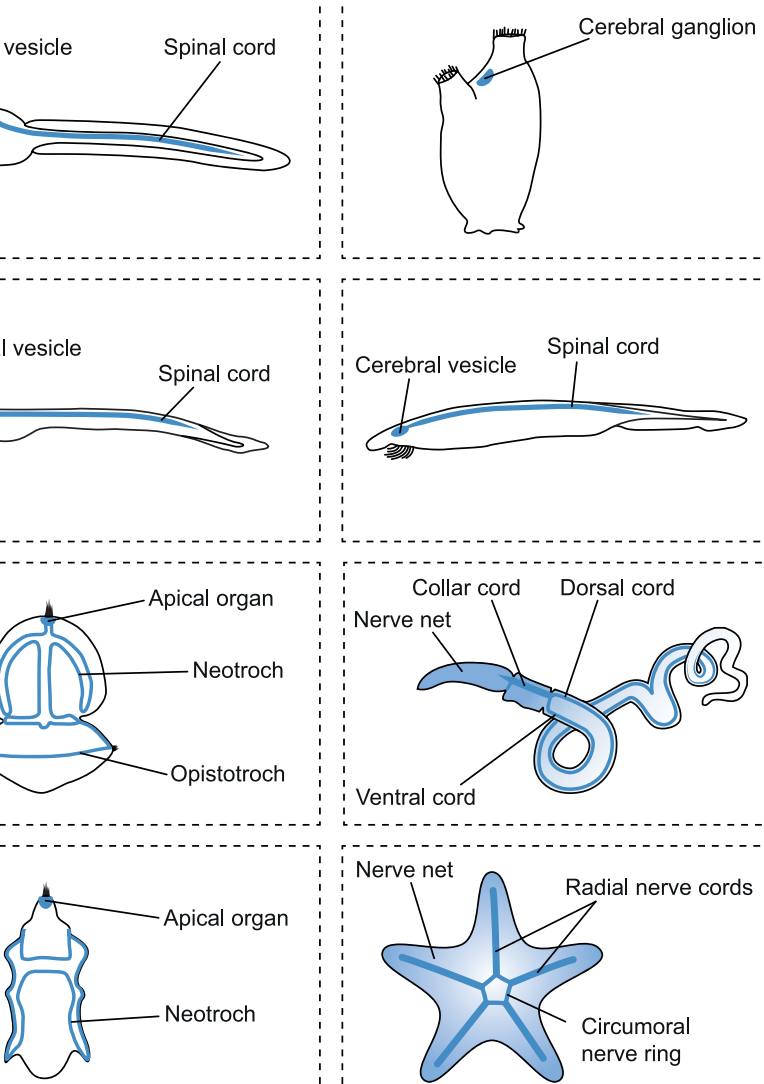

Collar cord Dorsal cord
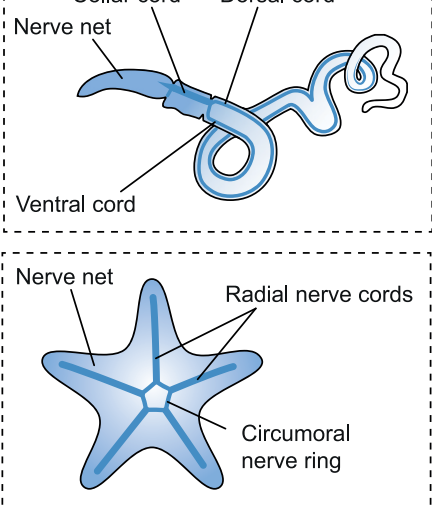


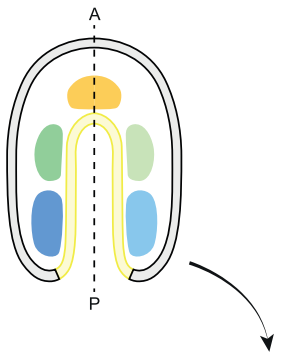

Late echinoderm larva

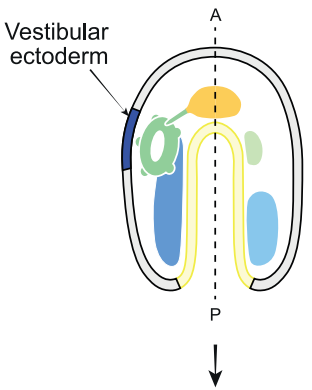

Adult echinoid

Adult enteropneust
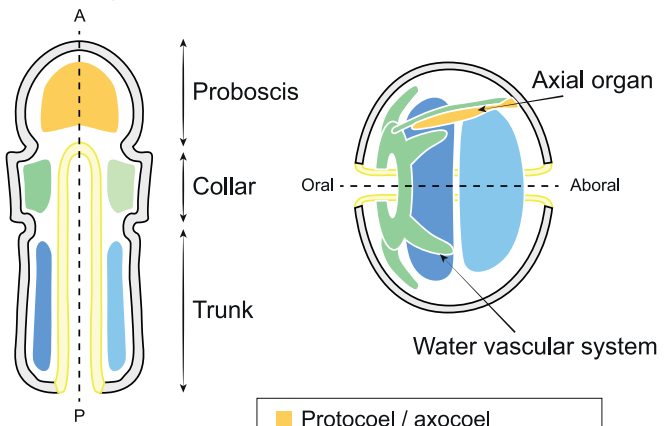

Protocoel / axocoel

- Left mesocoel / hydrocoel

Right mesocoel / hydrocoel

- Left metacoel / somatocoel

Right metacoel / somatocoel 


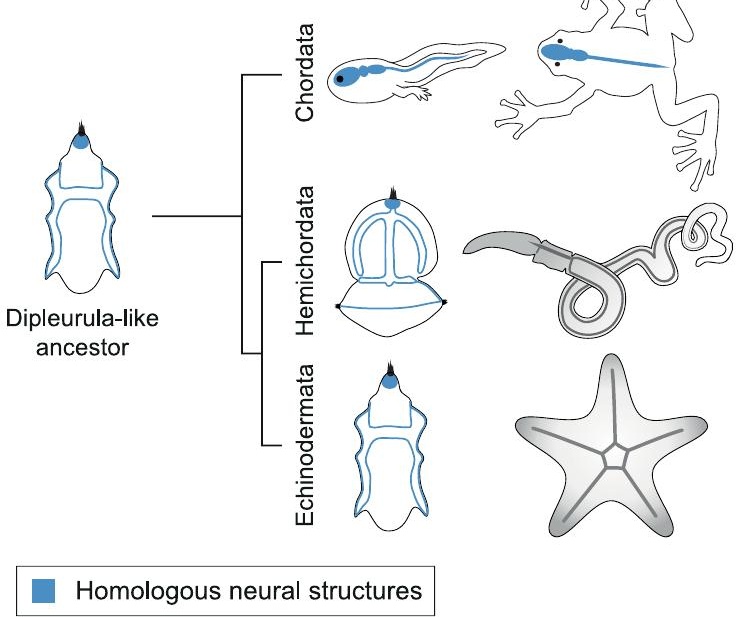




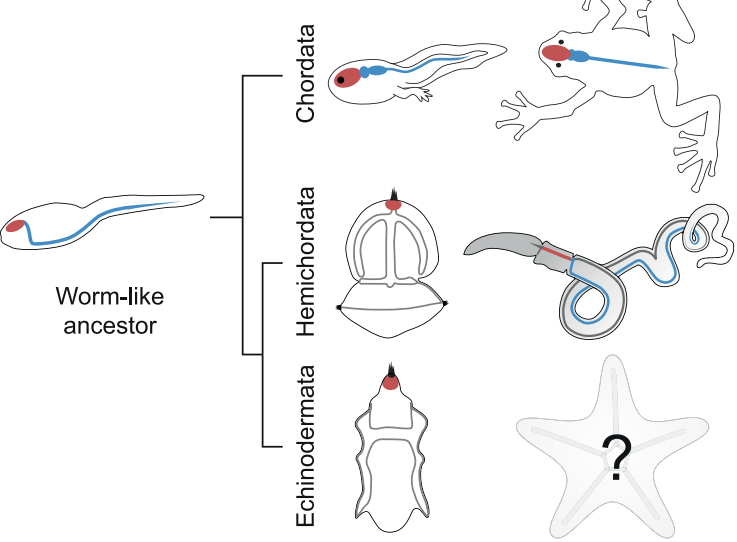




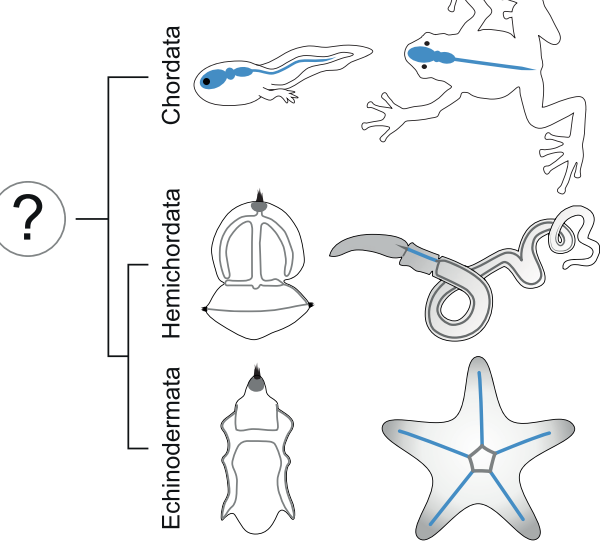

\section{Homologous neural structures}




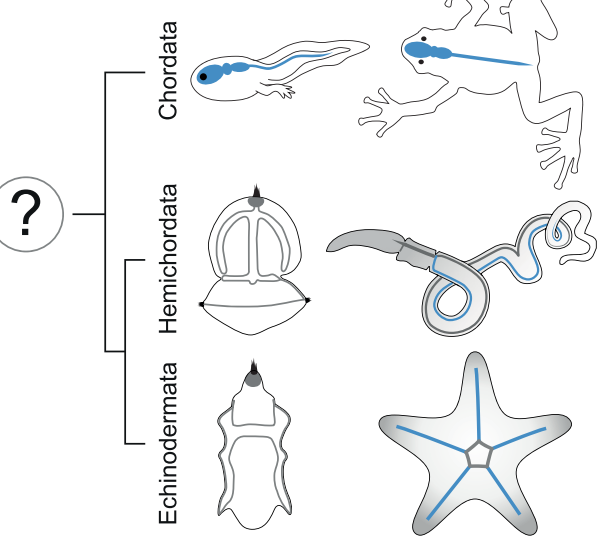

\section{Homologous neural structures}


